\title{
Using acoustic telemetry to assess behavioral responses to acute hypoxia and ammonia exposure in farmed rainbow trout of different competitive ability
}

Gesto, Manuel; Zupa, Walter; Alfonso, Sébastien; Spedicato, Maria Teresa; Lembo, Giuseppe; Carbonara, Pierluigi

Published in:

Applied Animal Behaviour Science

Link to article, DOI:

10.1016/j.applanim.2020.105084

Publication date:

2020

Document Version

Peer reviewed version

Link back to DTU Orbit

Citation (APA):

Gesto, M., Zupa, W., Alfonso, S., Spedicato, M. T., Lembo, G., \& Carbonara, P. (2020). Using acoustic telemetry to assess behavioral responses to acute hypoxia and ammonia exposure in farmed rainbow trout of different competitive ability. Applied Animal Behaviour Science, 230, [105084].

https://doi.org/10.1016/j.applanim.2020.105084

\section{General rights}

Copyright and moral rights for the publications made accessible in the public portal are retained by the authors and/or other copyright owners and it is a condition of accessing publications that users recognise and abide by the legal requirements associated with these rights.

- Users may download and print one copy of any publication from the public portal for the purpose of private study or research.

- You may not further distribute the material or use it for any profit-making activity or commercial gain

- You may freely distribute the URL identifying the publication in the public portal 


\section{Journal Pre-proof}

Using acoustic telemetry to assess behavioral responses to acute hypoxia and ammonia exposure in farmed rainbow trout of different competitive ability

Manuel Gesto, Walter Zupa, Sébastien Alfonso, Maria Teresa Spedicato, Giuseppe Lembo, Pierluigi Carbonara

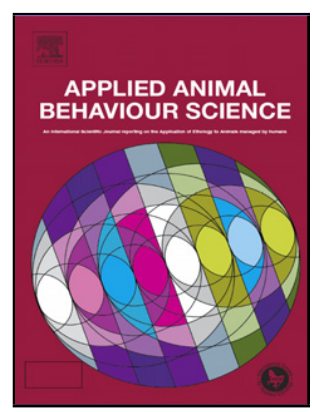

PII:

S0168-1591(20)30172-6

DOI:

https://doi.org/10.1016/j.applanim.2020.105084

Reference:

APPLAN 105084

To appear in:

Applied Animal Behaviour Science

Received Date: 13 January 2020

Revised Date: $\quad 25$ May 2020

Accepted Date: $\quad 8$ July 2020

Please cite this article as: Gesto M, Zupa W, Alfonso S, Spedicato MT, Lembo G, Carbonara $P$, Using acoustic telemetry to assess behavioral responses to acute hypoxia and ammonia exposure in farmed rainbow trout of different competitive ability, Applied Animal Behaviour Science (2020), doi: https://doi.org/10.1016/j.applanim.2020.105084

This is a PDF file of an article that has undergone enhancements after acceptance, such as the addition of a cover page and metadata, and formatting for readability, but it is not yet the definitive version of record. This version will undergo additional copyediting, typesetting and review before it is published in its final form, but we are providing this version to give early visibility of the article. Please note that, during the production process, errors may be discovered which could affect the content, and all legal disclaimers that apply to the journal pertain.

(C) 2020 Published by Elsevier. 


\section{Using acoustic telemetry to assess behavioral responses to acute hypoxia and ammonia exposure in farmed rainbow trout of different competitive ability}

Manuel Gesto ${ }^{a^{*}}$, Walter Zupa ${ }^{b}$, Sébastien Alfonso ${ }^{b}$, Maria Teresa Spedicato ${ }^{b}$, Giuseppe Lembo ${ }^{b}$, Pierluigi Carbonarab

aSection for Aquaculture, The North Sea Research Centre, DTU Aqua, Technical University of Denmark, Willemoesvej 2, 9850 Hirtshals, Denmark.

${ }^{b}$ COISPA Tecnologia \& Ricerca, via dei Trulli 18-20, 70126 Bari, Italy.

*Corresponding author:

Manuel Gesto

E-mail: mges@aqua.dtu.dk

\section{Highlights}

- Trout of different personality/competitive ability were exposed to aquaculture stressors (hypoxia and high ammonia).

- The behavioral response to stressors was evaluated by both video-monitoring and telemetry (wireless accelerometer sensors).

- Hypoxia resulted overall in reduced swimming activity, but induced no physiological stress.

- High levels of ammonia were stressful, and induced an increase of avoidance behavior.

- Personality-related behavioral differences were evident upon stress (high ammonia).

- The data support the use of wireless accelerometer sensors as a promising tool for welfare monitoring in aquaculture.

\section{Abstract}


As other vertebrates, fish differ on an individual basis in their responses to disturbance (i.e. stress) and in their capacity for adaptation to environmental change. This individual stress-coping style (SCS) might have an impact on the individual welfare in aquaculture facilities. However, most of the studies about the behavioral and physiological stress responses of fish with different SCS were performed under conditions very unlike usual rearing conditions. Therefore, we aimed in the current study at investigating the behavioral and physiological responses of rainbow trout (Oncorhynchus mykiss) of different SCS to common aquaculture stressors (exposure to hypoxia or high ammonia) under realistic conditions. We first screened the fish according to their competitive ability, as a proxy of SCS, separating the best and worst competitors (winners, W, and losers, L, respectively). Then, we evaluated the behavioral (using both telemetric and video-monitoring approaches ) and physiological response of both groups upon exposure to increasing levels of hypoxia and ammonia. Overall, increasing hypoxia induced a slight but progressive decrease in fish activity, independently of the fish SCS. High concentrations of total ammonia induced an increase of certain behavioral displays, such as swimming bursts or approaches to the surface, the latter being overall more frequent in W than in L fish. At the specific stress levels tested (hypoxia: 50 \% oxygen saturation; total ammonia: $2.91 \mathrm{mM}$ ), the physiological stress markers showed that the behavioral response to ammonia was probably driven by stress, while the behavioral response of the fish to hypoxia was just a behavioral adjustment to accommodate the decrease in oxygen availability. In conclusion, our data show that fish of different competitive ability showed similar activity patterns in routine conditions or when adapting to non-stressful conditions ( $50 \%$ oxygen saturation) in an aquaculture-like setup, but differed in their behavioral response when exposed to stress (high water ammonia). In addition, our data support the use of acoustic accelerometer transmitters as a promising tool for real-time monitoring of fish welfare in commercial fish farms.

KEYWORDS: fish, stress coping style, behavior, wireless sensors, aquaculture, stress.

\section{Introduction}


Fish, as other vertebrates, differ on an individual basis in their behavior and in their capacity for adaptation to environmental change (Koolhaas et al., 1999). This individuality might have an impact on the individual growth and welfare in aquaculture facilities, since the discomfort of the fish when facing a stressor, and therefore, its consequences, could be different depending on the individual (Richter and Hintze, 2019). Vertebrate individuals are usually classified as being of more proactive or reactive stress-coping style (SCS) depending on whether they display active or passive responses, respectively, when facing stressors (Castanheira et al., 2017; Koolhaas et al., 2010, 1999). Other behavioral traits have been shown to appear often associated to this active-passive duality, in such a way that proactive individuals tend to be bolder, more aggressive and more dominant than reactive individuals, which in turn have been frequently shown to display a more flexible behavior than reactive ones (Castanheira et al., 2017; Höglund et al., 2017; Ruiz-Gomez et al., 2008). Whether the SCS of the fish generate individual welfare differences is still under study. Currently, there is controversial data in the literature about the association between the behavioral and physiological responses to stress in fish. Some studies suggested that the proactive coping style might be associated to a lower activation of the hypothalamus-pituitary-interrenal (HPI) neuroendocrine axis upon acute stress than reactive fish (Castanheira et al., 2017; Winberg et al., 2016), which raises the question of whether proactive fish might be more resilient to stress. On the other hand, several recent studies have not found such associations between SCS and the $\mathrm{HPI} /$ cortisol response to acute stress (Boulton et al., 2015; Gesto, 2019; Vaz-Serrano et al., 2011). Nevertheless, most of the studies about the stress responses of fish with different SCS are usually performed under conditions that differ to a large extent to their normal rearing conditions. This includes, for example, exposing the fish individually to isolation/confinement (Backström et al., 2014; Gesto, 2019; Kittilsen et al., 2009; Øverli et al., 2004; Alfonso et al., 2019), situation that a fish will rarely experience in an aquaculture setup.

While the physiological response to stress of fish of different coping style has been thoroughly studied, no much data is available about the behavioral stress responses of fish of different personality. As mentioned above, data 
about the fish behavioral stress responses under aquaculture-like conditions is even scarcer (Colson et al., 2019, 2015; Sadoul et al., 2017, 2014). This is probably due to the inherent difficulties of studying/monitoring fish behavior (traditionally done by video-analysis), particularly when there is a high number of individuals in the fish rearing unit. Besides video monitoring technology, it is nowadays possible to monitor fish behavior by means of different kinds of electronic tags able to measure and store or transmit different behavioral and/or metabolic variables, such as positioning, speed, acceleration, heart rate, respiratory rate, muscle activity, etc. (Carbonara et al., 2015; Cooke et al., 2016; Lennox et al., 2017). Traditionally used in wild fish as a key source of information for conservation and management practices in aquatic ecology (Fuchs and Caudill, 2019; Lennox et al., 2017; McKenzie et al., 2016), these electronic tags are also a promising tool for refining farming procedures for a better monitoring and control of fish welfare in aquaculture facilities (Brijs et al., 2018; Carbonara et al., 2020, 2019a; Kolarevic et al., 2016; Martos-Sitcha et al., 2019).

We recently showed that juvenile trout groups differing in their competitive ability (assumed to be of different SCS) had no apparent differences in their physiological response to stress or in their ability to grow when reared at high stocking density and with plenty of food available (i.e. aquaculture-like conditions) (Gesto, 2019). In that study, the behavioral and physiological stress responses of the SCS groups were tested in isolation, a situation fish are not expected to face in an aquaculture setup. In the current study, we aimed at investigating the behavioral and physiological response of fish of different competitive ability to common aquaculture stressors in a more realistic scenario. We hypothesized that individuals of different coping style could be differentially affected by aquaculture stressors. If that is the case, a behavioral selection of farmed fish could be a tool to improve animal welfare in fish farms. We exposed the fish groups to common aquaculture stressors, such as hypoxia and high ammonia levels, always keeping the fish in their rearing units in normal aquaculture-like conditions. In order to screen fish behavior, some individuals of each group were implanted with acoustic accelerometer transmitters. The behavior of the fish was then monitored by both telemetric and video- 
monitoring approaches upon increasing levels of hypoxia and ammonia. Finally, physiological stress markers (i.e. cortisol, glucose and lactate concentrations in plasma; telencephalic serotonergic activity) were also evaluated at a specific level of each stressor in order to investigate the potential link between the behavioral and physiological responses of the fish competitive groups.

\section{Materials and methods}

\subsection{Animals}

Rainbow trout (Oncorhynchus mykiss) juveniles of approx. $100 \mathrm{~g}$ of mass were purchased at a local farm (Funderholme dambrug, Silkeborg, Denmark) and transported to DTU Aqua's facilities in Hirtshals (Denmark). Fish $(n=700)$ were kept in six $600 \mathrm{~L}$ tanks in a recirculated water system at $15^{\circ} \mathrm{C}$. Water quality in terms of $\mathrm{pH}$ $(7.7-8.2), \mathrm{NH}_{4}^{+}\left(<0.5 \mathrm{mg} \mathrm{L}^{-1}\right), \mathrm{NO}_{2}^{-}\left(<0.15 \mathrm{mg} \mathrm{L}^{-1}\right), \mathrm{NO}_{3}^{-}\left(<100 \mathrm{mg} \mathrm{L}^{-1}\right), \mathrm{O}_{2}$ saturation $(>80 \%)$ was daily monitored. Fish were daily fed a commercial trout feed (EFICO E 920, Biomar, Brande, Denmark; $1 \%$ body mass day ${ }^{-1}$ ) by means of belt feeders. After five weeks of acclimation, the selection process began as explained below. The use of fish in this study complied with Danish and EU legislation (Directive 2010/63/EU) on the use of animals for scientific purposes.

\subsection{Screening of loser and winner fish according to their competitive ability}

Fish were selected according to their ability to compete for food under conditions of low stocking density and reduced feed ratio, as described elsewhere (Gesto, 2019). Briefly, groups of 20 size-matched individuals (mass \% C.V. was always $<15 \%$, for any given tank) were allocated in $600 \mathrm{~L}$ tanks and were reared for 12 days in conditions promoting competition for food: low stocking density and a limited food ration of $0.5 \%$ fish mass day ${ }^{-1}$, provided by means of $12 \mathrm{~h}$ belt feeders. After the 12 day-period, the three-four individuals showing the best and worst 
ability to compete, based on the individual specific growth ratio (SGR) were selected as winner (W) and loser (L) fish, respectively. Several rounds of selection were completed in an eight-week period (see Figure 1 for a schedule of the study), and $n=89 \mathrm{~W}$ and $\mathrm{n}=89 \mathrm{~L}$ fish were selected (from among a total of $\mathrm{n}=500$ screened fish; the competition trial was repeated 25 times in total). The $W$ and $L$ fish were then kept in separate tanks (two tanks per group, four tanks in total). The mean (SD) size of the fish at the time of selection was $178.2 \mathrm{~g}$ (53.6 g) and $162.5 \mathrm{~g}(46.2 \mathrm{~g})$ for $\mathrm{W}$ and L fish respectively, and the stocking density (SD) by the end of the selection process was $14.3 \mathrm{~kg} \mathrm{~m}^{-3}\left(1.7 \mathrm{~kg} \mathrm{~m}^{-3}\right)$. After screening, all fish were daily fed at a ration of $1.5 \%$ body mass day ${ }^{-1}$ (EFICO E 920, Biomar, Brande, Denmark).

\subsection{Tag implants and swimming activity monitoring}

Four weeks after the end of the selection process, five $L$ and five $W$ fish were implanted with VEMCO V9A accelerometer transmitters (AMIRIX Systems Inc., Nova Scotia, Canada). Transmitters were surgically implanted under anesthesia (clove oil, $30 \mathrm{mg} \mathrm{L}^{-1}$ ) in the intraperitoneal cavity of the fish through a $1.5 \mathrm{~cm}$ incision as described elsewhere (Carbonara et al., 2019a, 2015; Cruz-Font et al., 2016). After implantation, the fish were allowed to recover together in a separate tank for five days. Transmitters were operated in "tailbeat" mode, i.e. acceleration was measured on two spatial axes $(\mathrm{X}, \mathrm{Z})$, ignoring the backward/forward acceleration ( $\mathrm{Y}$ axis), in order to account for the undulation movements during fish swimming associated to the movements of the tail, which are known to be directly associated to fish' swimming speed (Cruz-Font et al., 2016; Wilson et al., 2013). The activity score (i.e. acceleration) values were calculated by the transmitters as RMS (root mean square) of the acceleration components for both axes, averaged over time. The transmitters were programmed to measure acceleration for $12 \mathrm{~s}$ windows (at a rate of 10 acceleration measurements per second, in each axis), every minute, and to then acoustically (69 kHz) transmit the signal to submergible acoustic receivers (Vemco VR2W) allocated inside the fish rearing tanks. Readers may refer to www.vemco.com for more details on transmitter operation. 
After recovery, the five implanted fish of each group were allocated together with 20 size-matched individuals of the corresponding competitive group. Then, the swimming activity was continuously monitored during the battery life of the transmitters. The monitored period included the hypoxia and ammonia exposure tests, as well as the intervals between them, as described below. The average mass (SD) of the fish at the time of implantation was $345.3 \mathrm{~g}(52.8 \mathrm{~g})$ and $340.5 \mathrm{~g}$ (58.1 g) in W and L fish, respectively.

\subsection{Behavioral responses to acute hypoxia and ammonia}

\subsubsection{Experimental design}

A total of four repetitions of the acute hypoxia tests and three repetitions of the acute ammonia tests were performed with the 25-fish groups, starting with acute hypoxia seven weeks after the end of the screening rounds (Figure 1). Hypoxia acute tests were carried out during a period of two weeks and intervals of at least three days were kept between tests for complete recovery of the fish. After the hypoxia tests, the ammonia exposure tests were carried out along a period of two weeks, keeping intervals of at least five resting days in between tests to allow the fish to recover.

The protocol used for the acute hypoxia test was as follows. The test started by keeping the fish in normal conditions, with the $\mathrm{O}_{2}$ saturation level at all times above $85 \%$, for at least 30 minutes. Afterwards the aeration probe was removed from the tank, and the saturation level started to decay steadily due to $\mathrm{O}_{2}$ consumption by the fish. The test was terminated when the saturation level reached $30 \%$, which took place between 170 min and $200 \mathrm{~min}$ after the start of the test. During the test, the $\mathrm{O}_{2}$ saturation level was continuously monitored with portable meters (Handy Polaris, OxyGuard ${ }^{\circledR}$, Farum, Denmark); the decay in saturation was linear and is illustrated in Supplementary Figure 1. The behavior of the animals was continuously registered by means of the V9A transmitters. Furthermore, a zenithal video of the whole test was obtained using an HP® HD-3100 webcam (HP, USA). 
The protocol used for the acute ammonia test was as follows. The test started by keeping the animals for 20 min in normal conditions, with undetectable levels of total ammonia (TA: $\mathrm{NH}_{4}{ }^{+}+\mathrm{NH}_{3} ;<0.01 \mathrm{mM}$; MQuant ${ }^{\oplus}$ Ammonium test, Merck, Darmstadt, Germany). The amount of TA in the tank was then increased by adding ammonium chloride ( $\mathrm{NH}_{4} \mathrm{Cl}$; BASF SE, Ludwigshafen, Germany) in steps, as indicated in Table 3. The TA levels in the water were increased every 20 min for a total of four $\mathrm{NH}_{4} \mathrm{Cl}$ additions, resulting in an $\mathrm{NH}_{4} \mathrm{Cl}$ concentration of $3.89 \mathrm{mM}$ by the end of the trial. Table 3 also shows the corresponding levels of unionized ammonia (in the form of $\mathrm{NH}_{3}$ ) during the test, which were calculated based on the TA values and water $\mathrm{pH}$ (Bower and Bidwell, 1978). The increase in $\mathrm{NH}_{3}-\mathrm{N}$ was not linear due to the drift of the $\mathrm{pH}$ after $\mathrm{NH}_{4} \mathrm{Cl}$ addition to the tanks. Table 3 shows nominal concentration for $\mathrm{TA}$ and $\mathrm{NH}_{3}$ in different units to facilitate comparisons with other studies. Water samples were taken at each step in each test for the estimation of the actual levels of unionized ammonia in the water, which were consistent with the nominal concentrations. Unionized ammonia levels were within the range reported for $96 \mathrm{~h} \mathrm{LC50} \mathrm{in} \mathrm{rainbow} \mathrm{trout} \mathrm{and} \mathrm{other} \mathrm{fish} \mathrm{species} \mathrm{(Person-Le} \mathrm{Ruyet} \mathrm{et} \mathrm{al.,} \mathrm{1995;} \mathrm{Shingles} \mathrm{et} \mathrm{al.,} \mathrm{2001;}$ Thurston and Russo, 1983). The same as in the hypoxia tests, the behavior of the fish was continuously monitored by video recording and by the V9A transmitters.

\subsubsection{Analysis of video-recorded behavior}

Measurements of fish activity were estimated from zenithal videos recorded during the hypoxia and high ammonia behavioral tests described above. For hypoxia, the activity of the fish was quantified from 1 min long video clips at specific moments of the test. Specifically, 1 min clips were obtained at the middle of the initial "basal activity period" (i.e. $>85 \%$ of $\mathrm{O}_{2}$ saturation), and then at the moments when the oxygen saturation level was at $80 \%, 65 \%, 50 \%$ and $35 \%$. In those clips, the trajectory of four, randomly-chosen individual fish was obtained using Solomon Coder (C), v. 17.03.22 (www.solomoncoder.com) and then the path length measured 
using the "measure path" utility in Inkscape v. 0.92 (www.inkscape.org). Distance covered is therefore expressed in arbitrary units.

Similarly, distance covered during the ammonia test was evaluated in each of the steps as ammonia levels increased. Again, 1 min clips were extracted from the general video, always 5 min before a new addition of $\mathrm{NH}_{4} \mathrm{Cl}$ to the tank. Therefore, clips were obtained at $15 \mathrm{~min}$ (basal), $35 \mathrm{~min}, 55 \mathrm{~min}, 75 \mathrm{~min}$ and $95 \mathrm{~min}$, accounting for the different exposure levels as shown in Table 3. As described for the hypoxia tests, four random individuals were followed and the distance they covered was quantified. In the case of these high ammonia tests, the number of activity bursts and the number of fish' approaches to the surface were also quantified on a tank basis in each of the TAN incremental steps. Those behaviors were monitored in the 4-min period preceding the addition of $\mathrm{NH}_{4} \mathrm{Cl}$ to the tank (minutes 16 to 20,36 to 40,56 to 60,76 to 80 and 96 to 100 ).

\subsubsection{Telemetry data}

Signals about the fish swimming activity from the accelerometer transmitters were logged in the receivers allocated in the tanks. Data log consisted in a set of activity scores associated to transmission times. After synchronizing the receivers, the videos and the water quality data (oxygen saturation, TA), the activity of the fish could be directly associated to the level of the stressor of interest. During the hypoxia and ammonia exposure tests, the factor time was categorized and used as a discrete variable.

\subsection{Physiological response to acute hypoxia and ammonia exposure}

After the behavioral study, L and W fish were distributed in groups (three replicates per competitive group) of 25 to 27 fish, at a mean (SD) stocking density of $20.5 \mathrm{~kg} \mathrm{~m}^{-3}\left(1.7 \mathrm{~kg} \mathrm{~m}^{-3}\right)$. The individual mass (SD) of the fish was $492.9 \mathrm{~g}$ (55.5 g) and $494.3 \mathrm{~g}$ (32.0 g) for L and W fish respectively. After two weeks of acclimation, an experiment was performed to account for the level of stress physiological markers of $W$ and $L$ fish in response to acute 
hypoxia and ammonia exposure. The levels of hypoxia and high ammonia conditions for these experiments were chosen based on the minimum levels at which the fish showed a behavioral response in the previous experiments. All fish groups were first exposed to hypoxia and, five days later, they were all exposed to ammonia. The exposure protocols were similar to those applied in the behavior trials, with some differences: The hypoxia test was stopped when the $\mathrm{O}_{2}$ saturation levels reached $50 \%$ (i.e., first behavioral changes observed). At this point, $n=12$ fish of each competition group (four fish per replicate) were sampled to assess several physiological stress variables (i.e. plasma cortisol, glucose, lactate and telencephalic serotonergic activity). The ammonia exposure test was stopped 10 min after the water TAN levels were at $2.91 \mathrm{mM}$, after the third $\mathrm{NH}_{4} \mathrm{Cl}$-addition step. This time was chosen as it was equivalent to the midpoint in the 20-min step in the previous experiment. At this point, $\mathrm{n}=12$ fish per group (four fish per replicate) were sampled for physiological stress assessment. Control fish (three per tank; i.e. $\mathrm{n}=9$ per competition group) were sampled in the interval, 2 days after the hypoxia exposure trial, to assess the basal, unstressed levels of the stress markers. For sampling, fish were in every case gently netted from the tanks and deeply anesthetized ( $360 \mathrm{mg} \mathrm{L}^{-1}$ isoeugenol - Aqui-S ${ }^{\circledR}$, New Zealand). A sample of blood was collected from the tail blood vessels and then the brain of the fish was dissected out after decapitation. The telencephalon was collected and stored at $-80 \mathrm{C}$ until analysis. Blood was centrifuged for 10 $\min (5000 \times \mathrm{g}, 4 \mathrm{C})$ to collect the plasma, then stored at $-80^{\circ} \mathrm{C}$ until further analysis as described below.

Plasma levels of cortisol were analyzed with a commercial ELISA kit from Neogen Europe (Ayrshire, UK; Ref: 402710). Plasma glucose and lactate were analyzed using commercial colorimetric kits (Sigma, St. Louis, MO, USA; REFS: MAK013, MAK064). Serotonin (5-hydroxytyptamine, 5-HT) and 5-hydroxyindoleacetic acid (5-HIAA; main metabolite of $5-\mathrm{HT}$ ) were quantified in telencephalon by means of high-performance liquid chromatography (HPLC) with electrochemical detection, as previously described (Gesto et al., 2017). The turnover ratio between 5-HIAA and 5-HT was used to quantify the serotonergic system activity (Shannon et al., 1986). 


\subsection{Statistical analysis}

All statistical analyses were carried out at the $95 \%$ level of significance. The activity score (from the accelerometer tags) and the distance covered (obtained from the videos) were analyzed using a generalized linear mixed model (GLMM). GLMMs were carried out using the R 3.1.0 software (R Core team, 2013) and the Ime4 package (Bates et al., 2015). Since the activity score and distance covered are both strictly positive and continuous, we used a GLMM with Gamma distribution family and identity link. For the stress acute tests (i.e. hypoxia and ammonia exposure), the two variables competitive group $(\mathrm{L}, \mathrm{W})$ and stressor level $\left(\mathrm{O}_{2}\right.$ saturation levels for hypoxia tests, or TA levels for ammonia tests) were used as fixed factor, and fish ID and test repetition were both used as random factors when appropriated. Model selection was performed according to lowest AIC value, by discarding progressively the variable competitive group $(L, W)$ and then stressor level if they were not significant (Burnham and Anderson, 2002). When the GLMM was significant, it was followed by Tukey HSD post-hoc test. A visual inspection of the residuals was done for each model and revealed no particular violation of the statistical assumptions of the models. Only the best model for each variable (lowest AIC value) was further presented in the results section. Regarding the counts of activity bursts and approaches to the surface and the physiological markers, 2-way ANOVA was performed using treatment (control, hypoxia and high ammonia) and competitive group (L, W) as fixed factors. The Holm-Sidak test was used in every case for the post hoc comparisons. A nonparametric Kruskal -Wallis test, followed by a Dunn's post-hoc test was used to compare SGRs of the fish groups in the selection process. The 2-way ANOVAs and the Kruskal-Wallis test were all carried out with SigmaPlot v. 14.0 (Systat Software Inc., San Jose, CA, USA).

\section{Results}


Fish selected as W clearly outcompeted the L fish during the 12-day competition trials ( $p<0.001$, Dunn's test). The average (SD) SGR for $W$ and $L$ fish during the competition was $1.66(0.64) \%$ day $^{-1}$ and $-0.35(0.29) \%$ day $^{-1}$, respectively.

\subsection{Acute behavioral response to hypoxia}

Both video and V9A accelerometer data showed an effect of oxygen saturation level on fish activity, which generally decreased at low $\mathrm{O}_{2}$ concentrations (Table 2, Figure 4). Video-analysis showed a decrease in the distance covered by the selected fish at $50 \%$ and $35 \%$ saturation with respect to activity levels at $80 \%$ saturation and above (Figure 4A). Telemetry data showed lower swimming activity for the implanted fish at 30 to $50 \%$ saturation, when compared to activity levels found at above $60 \%$ saturation (Figure 4B). No competitive grouprelated differences were found in the telemetry data during exposure to hypoxia. However, the distance covered by $W$ fish in the videos was overall higher than that of $L$ fish during the whole experiment (Table 2, Figure $4 A$ ).

\subsection{Acute behavioral response to ammonia exposure}

Video-analysis data showed an initial decreasing trend in the distance covered as the levels of ammonia increased, reaching a minimum at $2.91 \mathrm{mM} \mathrm{NH}_{4} \mathrm{Cl}$ (Figure 5A). However, the distance covered by the fish showed a surge during the last part of the test, with the maximum levels of ammonia. The distance covered by the fish at $2.91 \mathrm{mM}$ of $\mathrm{NH}_{4} \mathrm{Cl}$ was significantly lower than at 0 and $3.89 \mathrm{mM}$. The competition group did not have any effect on the distance covered by the fish. Regarding the transmitter data, there was an interactive effect between both factors considered, the competition group and the ammonia concentration (Table 2 ). In $L$ fish, the swimming activity was constant during the whole experimental duration, while for $\mathrm{W}$ fish, the swimming activity was stable from 0 to $1.94 \mathrm{mM}$ of $\mathrm{NH}_{4} \mathrm{Cl}$, and became higher at high ammonia concentrations (Figure 5B); i.e. at 2.91 and $3.89 \mathrm{mM}$ of $\mathrm{NH}_{4} \mathrm{Cl}$. Furthermore, at the highest ammonia levels (2.91 mM and $\left.3.89 \mathrm{mM}\right)$, the W fish showed higher swimming activity levels than L fish. 
The ammonia concentration affected the number of swimming bursts $\left(F_{4,16}=25.89, p<0.001\right)$ and the number of approaches to the surface $\left(\mathrm{F}_{4,16}=22.89, p<0.001\right)$. The number of swimming bursts was higher at the highest ammonia dose, when compared to the rest of the doses, with no effect of competition group (Table 1, Figure 6A). The number of approaches to the surface was also higher at $3.89 \mathrm{mM} \mathrm{NH}_{4} \mathrm{Cl}$ than at all the lower ammonia concentrations (Figure 6B). In this case, there also was a main effect of the competition group $\left(\mathrm{F}_{1,16}=27.96, p=\right.$ 0.006), with $\mathrm{W}$ fish showing in general more approaches than L fish (Table 1, Figure 6B), but no differences between $\mathrm{W}$ and $\mathrm{L}$ fish were detected at any of the specific ammonia levels.

\subsection{Physiological response to hypoxia and ammonia exposure}

The treatment (control, hypoxia ammonia) affected the plasma levels of cortisol $\left(F_{2,12}=17.37, p<0.001\right)$ and lactate $\left(F_{2,12}=4.95, p<0.027\right)$. Plasma stress markers were not altered after exposing the fish to a steady decrease of oxygen saturation until $50 \%$ (Table 1, Figure 7). However, the exposure to increasing levels of ammonia up to $2.91 \mathrm{mM} \mathrm{NH}_{4} \mathrm{Cl}$ induced clear cortisol and lactate increases in the fish plasma, while glucose levels remained unchanged. The competitive group of the fish did not affect the response of the plasma stress markers to either hypoxia or ammonia (Table 1, Figure 7).

The treatment affected also the levels of serotonin $\left(F_{2,12}=4.20, p=0.042\right), 5-\mathrm{HIAA}\left(\mathrm{F}_{2,12}=9.84, p=0.003\right)$ and the serotonergic turnover ratio $\left(F_{2,12}=10.74, p=0.002\right)$ in the telencephalon. The latter was increased by ammonia exposure, while hypoxia induced no effects (Table 1, Figure 8). The levels of 5-HT were lower after exposure to ammonia when compared to controls. The levels of 5-HIAA were higher in fish exposed to ammonia than in in fish exposed to hypoxia, but neither was found to differ from control fish. There was also a significant main effect of the competitive group on the serotonin levels $\left(F_{1,12}=8.67, p=0.012\right)$, which were higher in the $\mathrm{W}$ than in the $L$ group.

\section{Discussion}


The competitive ability of fish can be considered as a proxy of the individual dominant/subordinate personality, which is related to the fish coping style (Castanheira et al., 2017; Gesto, 2019). Under captivity, the advantages or disadvantages of having a better or worse competitive ability depend on the context. During the competition trials, better competitors have a clear advantage, since they are able to get most of the food delivered to the tank. However, in usual conditions (higher stocking densities, large feed rations), competitive ability does not seem to affect trout growth rates, at least in undisturbed conditions (Gesto, 2019). We aimed here to explore whether the physiological and behavioral responses to hypoxia and ammonia (typical aquaculture stressors) under common aquaculture conditions differs between fish of different competitive ability. In order to discard the effects of a poor energy status of $L$ fish after the competition trials, the selected $L$ and $W$ fish were kept for some weeks in undisturbed conditions, so L fish could recover and regain normal growth rates, equivalent to those of $\mathrm{W}$ fish. Our data show that trout behavior was altered under acute sub-lethal exposure to hypoxia and ammonia. However, the only difference found in relation to the competitive ability of the individuals was related to a more active behavioral response of $W$ fish than $L$ fish when exposed to high levels of water ammonia. Besides, our data provide interesting insight about the combined use of video-monitoring and telemetry when assessing fish behavior in aquaculture tanks.

Hypoxia has been shown to induce differential, species-specific effects on fish spontaneous activity, depending on different factors such as "(1) aerobic capacity, (2) the nature of hypoxic stress (severity, duration of exposure), (3) the basal energy-demands of the fish or (4) benefits conferred by a change in swimming behavior (survival, escape/avoidance)" (Domenici et al., 2013). Further, for a given species, fish individuals have been shown to differ strongly in their behavioral responses to acute hypoxia (Chapman and Mckenzie, 2009; Killen et al., 2012; Van Raaij et al., 1996) and actually, the individual responses to hypoxia have been used as a tool to select fish of different coping behavior (Ferrari et al., 2016; Killen et al., 2012; Laursen et al., 2011). In our hypoxia challenge tests, both the distance covered and the swimming activity progressively decreased along with oxygen 
saturation, independently of the competition group of the fish. Likewise, other studies in salmonids and other teleost groups had found a decrease in activity under acute hypoxia (Alfonso et al., 2020; Chapman and Mckenzie, 2009; Israeli and Kimmel, 1996; Kolarevic et al., 2016; Via et al., 1998), which was attributed to a behavioral strategy to reduce the use of energy when oxygen availability was low (Chapman and Mckenzie, 2009). In contrast to our results, Poulsen et al. (2011) found an increase in swimming speed in rainbow trout under hypoxic conditions. However, in that study trout were given the choice between normoxic and hypoxic conditions, and it has been shown that the responses to hypoxia are also dependent on the possibilities to avoid/escape the hypoxic conditions (Cook and Herbert, 2012; Domenici et al., 2013). Fish of different coping style, within a given species, have been shown to differ in their behavioral response to hypoxia, as commented above. Proactive fish generally tend to escape faster from an environment becoming hypoxic (Ferrari et al., 2016; Herrera et al., 2014; Killen et al., 2012), but this is not always the case in salmonids (Laursen et al., 2011). In the current study, we did not observe differences in the swimming activity between the competitive groups using the telemetric data, while the distance covered evaluated from the videos was overall higher in $\mathrm{W}$ fish than $\mathrm{L}$ ones. This could be seen as a typical behavioral response of W (proactive-like) to actively cope with the stressor. Interestingly, different coping strategies upon hypoxia were observed between proactive and reactive sea bass (Alfonso, 2018); proactive fish tended to maximize the inter-individual distance within the shoal. This can be viewed as a strategy for enhancing oxygen uptake by going away from congeners (Domenici et al., 2017), possibly due to the higher metabolism of $W$ fish (Castanheira et al., 2017). Moreover, the distance covered among the fish is also linked to the different shoaling behavior of each species (Carbonara et al., 2019b; Krause et al., 2000).

In freshwater aquaculture facilities, TA levels increase in the water due to decomposition of organic matter by microorganisms and to the production of $\mathrm{NH}_{3}$ as a product of protein and purine metabolism of fish (McKenzie et al., 2009; Randall and Tsui, 2002). Ammonia is toxic to all vertebrates and, depending on the dose, ammonia intoxication can lead to hyperventilation, behavior alterations, convulsions and death (Eddy, 2005; McKenzie et 
al., 2009; Randall and Tsui, 2002; Wicks et al., 2002). Its toxicity is mainly related to the perturbation of the nervous system due to $\mathrm{NH}_{4}{ }^{+}$-induced neuron depolarization (Randall and Tsui, 2002). Among its toxic effects, exposure to ammonia has been demonstrated to affect the swimming performance in fish, an effect that is related to alterations on the function of the Mauthner cells and on the recruitment of white muscle (McKenzie et al., 2009; Wicks et al., 2002). To our knowledge, our study is one of the first reports on the effects of acute ammonia exposure on fish swimming activity. We obtained some contrasting data on fish swimming activity from video-analyses and telemetry data. The data on distance covered by the fish, obtained from the videos, showed a progressive decrease in the distance covered with increasing ammonia concentration from 0 to $2.91 \mathrm{mM}$ and a final surge at the highest ammonia concentration (3.89 mM). Telemetry data on the other hand, pointed to a clear increase of the activity of $W$ fish at high ammonia concentrations, while the activity score of $L$ fish remained unaffected. This inconsistency is probably related to the limitations of each monitoring system. High levels of water ammonia induced an increase in vertical movements and swimming bursts of the fish, mostly in the form of approaches to the surface. These behaviors can be easily counted from video-recordings of the tests (Figure 6), but the distance covered during these vertical movements is underestimated during the analysis of the videos, since zenithal videos do not provide an adequate perspective for movements in the vertical axis. This is probably the reason why the video data do not show an increase of activity at high ammonia in terms of distance covered with respect to the telemetry data and the counts of activity bursts and approaches to the surface. Both those counts and the telemetry data suggest that $\mathrm{W}$ fish respond more actively when exposed to highest ammonia doses than $L$ fish. From a behavioral point of view, this is consistent with the assumption of $W$ and $L$ fish as of proactive and reactive coping styles, and supports the use of competition ability as a tool to identify SCS in this species, as suggested before (Gesto, 2019).

Regarding the physiological stress responses of $W$ and $L$ fish, the tissue samples were collected at the stressor levels that generated the first behavioral response, based on the hypoxia and ammonia-exposure behavioral 
tests. Our data showed that acute exposure to ammonia was more stressful than the acute hypoxia in this experimental setup. Indeed, at a $50 \%$ oxygen saturation, both plasma (i.e. cortisol, glucose, lactate) and brain stress markers were at similar levels than control fish, suggesting that the fish were still not physiologically stressed at this level and that the reduction on activity was merely an adaptive response to better accommodate the decrease in oxygen availability. However, after increasing the water ammonia levels to $2.91 \mathrm{mM}$, the fish showed increases in plasma cortisol and lactate and in the serotonergic turnover in the telencephalon, indicating that they were under stressful conditions. Similar stress responses after both acute and/or prolonged ammonia exposure had been observed before in teleosts (Person-Le Ruyet et al., 1998; Spotte and Anderson, 1989; Taheri Mirghaed et al., 2019; Weber et al., 2012). The disturbance generated by the ammonia and the subsequent development of an integrated stress response are most probably generating the escaping/avoidance behavior of the fish, reflected in the observed increase of swimming bursts and approaches to the surface. It is important to highlight that no differences were found between $L$ and $W$ fish in the basal levels or in the responses of the different physiological stress indicators to hypoxia and ammonia. Diverse studies pointed to a correlation between the SCS of an individual and the magnitude of the post-stress activation of the main neuroendocrine stress axes: the hypothalamus-pituitary-interrenal (HPI), responsible for the release of cortisol, and the hypothalamus-sympathetic nervous system-chromaffin cells axis (BSC), responsible for the release of catecholamines (Wendelaar Bonga, 1997). It was suggested that proactive animals show a higher activation of the BSC axis and a lower activation of the HPI axis upon stress exposure than reactive fish (Castanheira et al., 2017; Winberg et al., 2016; Wong et al., 2019). This view is currently controversial and has been recently questioned by several studies showing a decoupling between the behavioral coping style and the magnitude of the response of stress hormones in fish (Boulton et al., 2015; Gesto, 2019; Qu et al., 2018; Vaz-Serrano et al., 2011). This study seems to support such a decoupling, but our data should be considered with caution since the competitive ability is used here as a proxy of SCS, but the SCS of the fish has not been explicitly stablished. In the 
present study, we observed that W fish (proactive-like) overall displayed higher level of 5-HT regardless of stress condition, while the serotonergic turnover ratio remained equal for both groups. The reason behind that difference is not known, but it was not observed in a previous study in which $L$ and $W$ fish were selected in the same way as in the current study (Gesto, 2019). Nevertheless, altogether, the data collected in this study mainly supports a lack of correlation between the competitive ability and the magnitude of the physiological stress response, even when some divergences in behavioral response were observed. In summary, we saw that the behavioral differences between of $L$ and $W$ fish only become noticeable when the fish were under stressful conditions (ammonia exposure), but no competition-related differences were observed in the physiological stress indicators, or in the fish activity under unchallenged conditions. It is important to notice that these experiments were carried out at relatively low stocking densities, when compared to those reached in intensive farms. Whether higher stocking densities might have an effect on the differential responses of $W$ and $L$ fish remains to be investigated.

Under stress conditions, the response of the organism comprises a complex array of changes, from the cellular to whole organism level, helping fish to cope with the disturbance. The combined use of physiological markers and the monitoring of functional indicators, such as swimming activity measured by accelerometer transmitter (Brownscombe et al., 2018; Cooke et al., 2004; Zupa et al., 2015), provides a more comprehensive picture of fish condition and behavior (Carbonara et al., 2019b, 2015; Lembo et al., 2007). Therefore, the simultaneous collection of both behavioral and physiological data is critical to increase the current understanding about the use of fish behavior as a potential stress and welfare indicator (Sadoul et al., 2015). In this regard, there is a need to increase the amount of data available and telemetry technology could be an optimal tool to carry out this kind of research in the years to come. Using both telemetry and video analysis together in this study has provided good insight about the strengths and weaknesses of each method. Video monitoring allows for a precise evaluation of fish swimming behavior but at the cost of requiring very specific conditions for video recording 
(Kolarevic et al., 2016). For example, current commercially available software for automatic coding of behavior into numerical measurements has specific visual requirements in terms of characteristics of the behavioral "arena" (size, depth, illumination, contrast, etc.) and fish numbers, in order to be able to quantify the behavior of several fish simultaneously. Several of those requirements are incompatible with aquaculture-like conditions, which usually consist of relatively deep tanks containing high fish numbers, in many cases dimly illuminated. Acoustic telemetry is not limited by visual factors (e.g. illumination or water turbidity) and allows continuous monitoring in rearing tanks at any stocking density and even in the dark. Further, data from the accelerometer transmitters are not affected by the direction of movement of the animal, while the estimation of activity from videos can be affected by the orientation of the movements with respect to the camera, as discussed above. Data analysis is time-consuming in the case of video monitoring, while telemetry data are acquired in real time. However, current telemetry technology and the potential use of implanted sentinel fish in aquaculture facilities is not free of limitations (Kolarevic et al., 2016). Those include the elevated price of the transmitters and their limited life, the relatively complex and invasive nature of implantation, and the limitation in the size of the fish that can bear the transmitters. Current level of miniaturization of the accelerometer transmitters makes only possible to use them in relatively large fish (Kolarevic et al., 2016). Nevertheless, the potential of wireless physiological sensors as a fish welfare-monitoring tool is huge, and future technical improvements will probably buffer most of those disadvantages in the near future.

In conclusion, our data show that fish of different competitive ability/coping style showed similar activity patterns in routine conditions or when adapting to non-stressful conditions (50\% oxygen saturation) in an aquaculture-like setup, but differed in their behavioral response when exposed to stress (high water ammonia). In stressful conditions (high water TAN), better competitors (W) showed a more active behavioral response than fish of lower competitive ability (L). However, the difference in the behavioral response of $L$ (reactive-like) and W (proactive-like) fish to stress was not reflected in the magnitude of the response of the physiological stress 
markers tested, pointing to a decoupling between behavioral and endocrine stress responses. Altogether, the obtained data suggest that fish of different competitive ability might have had a differential behavioral coping style, but their sensitivity to the tested stressors was similar. Furthermore, our data support the use of acoustic accelerometer transmitters as a promising potential tool for real-time monitoring of fish activity in commercial fish farms, but further technical advancements in accelerometer transmitter miniaturization would help to extend their use in the aquaculture industry.

\section{Acknowledgements}

This study was funded by ANIHWA ERA-Net (WIN-FISH), the Italian Ministry of Health (Department for public veterinary health, nutrition and food safety - Id project - 54 Welfare, Health and Individuality in Farmed FISH) and Innovation Fund Denmark (4200-00002B). The help of Rasmus Frydenlund Jensen and Ole Madvig Larsen for fish husbandry in Hirtshals was greatly appreciated.

\section{References}

Alfonso, S., 2018. Thèse de doctorat: Interactions entre traits de personnalité des téléostéens, environnement et polluants. Université de Montpellier, Montpellier.

Alfonso, S., Sadoul, B., Cousin, X., Bégout, M.L., 2020. Spatial distribution and activity patterns as welfare indicators in response to water quality changes in European sea bass, Dicentrarchus labrax. Appl. Anim. Behav. Sci. https://doi.org/10.1016/j.applanim.2020.104974

Backström, T., Brännäs, E., Nilsson, J., Magnhagen, C., 2014. Behaviour, physiology and carotenoid pigmentation in Arctic charr Salvelinus alpinus. J. Fish Biol. https://doi.org/10.1111/jfb.12240 
Bates, D., Mächler, M., Bolker, B.M., Walker, S.C., 2015. Fitting linear mixed-effects models using Ime4. J. Stat. Softw. https://doi.org/10.18637/jss.v067.i01

Boulton, K., Couto, E., Grimmer, A.J., Earley, R.L., Canario, A.V.M., Wilson, A.J., Walling, C.A., 2015. How integrated are behavioral and endocrine stress response traits? A repeated measures approach to testing the stress-coping style model. Ecol. Evol. https://doi.org/10.1002/ece3.1395

Bower, C.E., Bidwell, J.P., 1978. Ionization of Ammonia in Seawater: Effects of Temperature, pH, and Salinity. J. Fish. Res. Board Canada 35, 1012-1016. https://doi.org/10.1139/f78-165

Brijs, J., Sandblom, E., Axelsson, M., Sundell, K., Sundh, H., Huyben, D., Broström, R., Kiessling, A., Berg, C., Gräns, A., 2018. The final countdown: Continuous physiological welfare evaluation of farmed fish during common aquaculture practices before and during harvest. Aquaculture. https://doi.org/10.1016/j.aquaculture.2018.06.081

Brownscombe, J.W., Lennox, R.J., Danylchuk, A.J., Cooke, S.J., 2018. Estimating fish swimming metrics and metabolic rates with accelerometers: the influence of sampling frequency. J. Fish Biol. https://doi.org/10.1111/jfb.13652

Burnham, K.P., Anderson, D.R., 2002. Model Selection and Multimodel Inference: a Practical Informationtheoretic Approach, 2nd edn. Springer-Verlag, New York, New York Springer.

Carbonara, P., Alfonso, S., Gai, F., Gasco, L., Palmegiano, G., Spedicato, M.T., Zupa, W., Lembo, G., 2020. Moderate stocking density does not influence the behavioural and physiological responses of rainbow trout (Oncorhynchus mykiss) in organic aquaculture. Aquac. Res. https://doi.org/10.1111/are.14640

Carbonara, P., Alfonso, S., Zupa, W., Manfrin, A., Fiocchi, E., Pretto, T., Spedicato, M.T., Lembo, G., $2019 a$. Behavioral and physiological responses to stocking density in sea bream (Sparus aurata): Do coping styles 
matter? Physiol. Behav. https://doi.org/10.1016/j.physbeh.2019.112698

Carbonara, P., Dioguardi, M., Cammarata, M., Zupa, W., Vazzana, M., Spedicato, M.T., Lembo, G., 2019b. Basic knowledge of social hierarchies and physiological profile of reared sea bass Dicentrarchus labrax (L.). PLoS One. https://doi.org/10.1371/journal.pone.0208688

Carbonara, P., Scolamacchia, M., Spedicato, M.T., Zupa, W., Mckinley, R.S., Lembo, G., 2015. Muscle activity as a key indicator of welfare in farmed European sea bass (Dicentrarchus labrax L. 1758). Aquac. Res. https://doi.org/10.1111/are.12369

Castanheira, M.F., Conceição, L.E.C., Millot, S., Rey, S., Bégout, M.L., Damsgård, B., Kristiansen, T., Höglund, E., $\varnothing$ verli, $\varnothing$., Martins, C.I.M., 2017. Coping styles in farmed fish: consequences for aquaculture. Rev. Aquac. https://doi.org/10.1111/raq.12100

Chapman, L.J., Mckenzie, D.J., 2009. Behavioral Responses and Ecological Consequences, in: Fish Physiology. https://doi.org/10.1016/S1546-5098(08)00002-2

Colson, V., Mure, A., Valotaire, C., Le Calvez, J.M., Goardon, L., Labbé, L., Leguen, I., Prunet, P., 2019. A novel emotional and cognitive approach to welfare phenotyping in rainbow trout exposed to poor water quality. Appl. Anim. Behav. Sci. https://doi.org/10.1016/j.applanim.2018.10.010

Colson, V., Sadoul, B., Valotaire, C., Prunet, P., Gaumé, M., Labbé, L., 2015. Welfare assessment of rainbow trout reared in a Recirculating Aquaculture System: Comparison with a Flow-Through System. Aquaculture. https://doi.org/10.1016/j.aquaculture.2014.10.047

Cook, D.G., Herbert, N.A., 2012. The physiological and behavioural response of juvenile kingfish (Seriola lalandi) differs between escapable and inescapable progressive hypoxia. J. Exp. Mar. Bio. Ecol. https://doi.org/10.1016/j.jembe.2011.12.006 
Cooke, S.J., Brownscombe, J.W., Raby, G.D., Broell, F., Hinch, S.G., Clark, T.D., Semmens, J.M., 2016. Remote bioenergetics measurements in wild fish: Opportunities and challenges. Comp. Biochem. Physiol. -Part A Mol. Integr. Physiol. https://doi.org/10.1016/j.cbpa.2016.03.022

Cooke, S.J., Thorstad, E.B., Hinch, S.G., 2004. Activity and energetics of free-swimming fish: Insights from electromyogram telemetry. Fish Fish. https://doi.org/10.1111/j.1467-2960.2004.00136.x

Cruz-Font, L., Shuter, B.J., Blanchfield, P.J., 2016. Energetic costs of activity in wild lake trout: a calibration study using acceleration transmitters and positional telemetry. Can. J. Fish. Aquat. Sci. https://doi.org/10.1139/cjfas-2015-0323

Domenici, P., Herbert, N.A., Lefrançois, C., Steffensen, J.F., McKenzie, D.J., 2013. The effect of hypoxia on fish swimming performance and behaviour, in: Swimming Physiology of Fish: Towards Using Exercise to Farm a Fit Fish in Sustainable Aquaculture. https://doi.org/10.1007/978-3-642-31049-2_6

Domenici, P., Steffensen, J.F., Marras, S., 2017. The effect of hypoxia on fish schooling. Philos. Trans. R. Soc. B Biol. Sci. https://doi.org/10.1098/rstb.2016.0236

Eddy, F.B., 2005. Ammonia in estuaries and effects on fish. J. Fish Biol. https://doi.org/10.1111/j.10958649.2005.00930.x

Ferrari, S., Horri, K., Allal, F., Vergnet, A., Benhaim, D., Vandeputte, M., Chatain, B., Bégout, M.-L., 2016. Heritability of Boldness and Hypoxia Avoidance in European Seabass, Dicentrarchus labrax. PLoS One 11, e0168506. https://doi.org/10.1371/journal.pone.0168506

Fuchs, N.T., Caudill, C.C., 2019. Classifying and inferring behaviors using real-time acceleration biotelemetry in reproductive steelhead trout ( Oncorhynchus mykiss ). Ecol. Evol. https://doi.org/10.1002/ece3.5634 
Gesto, M., 2019. Consistent individual competitive ability in rainbow trout as a proxy for coping style and its lack of correlation with cortisol responsiveness upon acute stress. Physiol. Behav. https://doi.org/10.1016/j.physbeh.2019.112576

Gesto, M., Skov, P. V., Jokumsen, A., 2017. Emergence time and skin melanin spot patterns do not correlate with growth performance, social competitive ability or stress response in farmed rainbow trout. Front. Neurosci. 11. https://doi.org/10.3389/fnins.2017.00319

Herrera, M., Castanheira, M.F., Conceição, L.E.C., Martins, C.I., 2014. Linking risk taking and the behavioral and metabolic responses to confinement stress in gilthead seabream Sparus aurata. Appl. Anim. Behav. Sci. https://doi.org/10.1016/j.applanim.2014.03.001

Höglund, E., Silva, P.I.M., Vindas, M.A., Øverli, $\varnothing$. ., 2017. Contrasting coping styles meet the wall: A dopamine driven dichotomy in behavior and cognition. Front. Neurosci. https://doi.org/10.3389/fnins.2017.00383

Israeli, D., Kimmel, E., 1996. Monitoring the behavior of hypoxia-stressed Carassius auratus using computer vision. Aquac. Eng. https://doi.org/10.1016/S0144-8609(96)01009-6

Killen, S.S., Marras, S., Ryan, M.R., Domenici, P., Mckenzie, D.J., 2012. A relationship between metabolic rate and risk-taking behaviour is revealed during hypoxia in juvenile European sea bass. Funct. Ecol. https://doi.org/10.1111/j.1365-2435.2011.01920.x

Kittilsen, S., Schjolden, J., Beitnes-Johansen, I., Shaw, J.C., Pottinger, T.G., Sørensen, C., Braastad, B.O., Bakken, M., Øverli, 2009. Melanin-based skin spots reflect stress responsiveness in salmonid fish. Horm. Behav. 56, 292-298. https://doi.org/10.1016/j.yhbeh.2009.06.006

Kolarevic, J., Aas-Hansen, Espmark, Baeverfjord, G., Terjesen, B.F., Damsgård, B., 2016. The use of acoustic acceleration transmitter tags for monitoring of Atlantic salmon swimming activity in recirculating 
aquaculture systems (RAS). Aquac. Eng. https://doi.org/10.1016/j.aquaeng.2016.03.002

Koolhaas, J.M., de Boer, S.F., Coppens, C.M., Buwalda, B., 2010. Neuroendocrinology of coping styles: Towards understanding the biology of individual variation. Front. Neuroendocrinol. https://doi.org/10.1016/j.yfrne.2010.04.001

Koolhaas, J.M., Korte, S.M., De Boer, S.F., Van Der Vegt, B.J., Van Reenen, C.G., Hopster, H., De Jong, I.C., Ruis, M.A.W., Blokhuis, H.J., 1999. Coping styles in animals: Current status in behavior and stress- physiology. Neurosci. Biobehav. Rev. 23, 925-935. https://doi.org/10.1016/S0149-7634(99)00026-3

Krause, J., Hoare, D.J., Croft, D., Lawrence, J., Ward, A., Ruxton, G.D., Godin, J.G.J., James, R., 2000. Fish shoal composition: Mechanism and constraints. Proc. R. Soc. B Biol. Sci. https://doi.org/10.1098/rspb.2000.1243

Laursen, D.C., L. Olsén, H., Ruiz-Gomez, M. de L., Winberg, S., Höglund, E., 2011. Behavioural responses to hypoxia provide a non-invasive method for distinguishing between stress coping styles in fish. Appl. Anim. Behav. Sci. 132, 211-216. https://doi.org/10.1016/j.applanim.2011.03.011

Lembo, G., Carbonara, P., Scolamacchia, M., Spedicato, M.T., McKinley, R.S., 2007. Use of muscle activity indices as a relative measure of well-being in cultured sea bass Dicentrarchus labrax (Linnaeus, 1758), in: Hydrobiologia. https://doi.org/10.1007/s10750-006-0538-9

Lennox, R.J., Aarestrup, K., Cooke, S.J., Cowley, P.D., Deng, Z.D., Fisk, A.T., Harcourt, R.G., Heupel, M., Hinch, S.G., Holland, K.N., Hussey, N.E., Iverson, S.J., Kessel, S.T., Kocik, J.F., Lucas, M.C., Flemming, J.M., Nguyen, V.M., Stokesbury, M.J.W., Vagle, S., Vanderzwaag, D.L., Whoriskey, F.G., Young, N., 2017. Envisioning the Future of Aquatic Animal Tracking: Technology, Science, and Application. Bioscience. https://doi.org/10.1093/biosci/bix098

Martos-Sitcha, J.A., Sosa, J., Ramos-Valido, D., Bravo, F.J., Carmona-Duarte, C., Gomes, H.L., Calduch-Giner, J.À., 
Cabruja, E., Vega, A., Ferrer, M.Á., Lozano, M., Montiel-Nelson, J.A., Afonso, J.M., Pérez-Sánchez, J., 2019. Ultra-Low Power Sensor Devices for Monitoring Physical Activity and Respiratory Frequency in Farmed Fish. Front. Physiol. https://doi.org/10.3389/fphys.2019.00667

McKenzie, D.J., Axelsson, M., Chabot, D., Claireaux, G., Cooke, S.J., Corner, R.A., De Boeck, G., Domenici, P., Guerreiro, P.M., Hamer, B., Jørgensen, C., Killen, S.S., Lefevre, S., Marras, S., Michaelidis, B., Nilsson, G.E., Peck, M.A., Perez-Ruzafa, A., Rijnsdorp, A.D., Shiels, H.A., Steffensen, J.F., Svendsen, J.C., Svendsen, M.B.S., Teal, L.R., van der Meer, J., Wang, T., Wilson, J.M., Wilson, R.W., Metcalfe, J.D., 2016. Conservation physiology of marine fishes: state of the art and prospects for policy. Conserv. Physiol. https://doi.org/10.1093/conphys/cow046

McKenzie, D.J., Shingles, A., Claireaux, G., Domenici, P., 2009. Sublethal Concentrations of Ammonia Impair Performance of the Teleost Fast-Start Escape Response. Physiol. Biochem. Zool. https://doi.org/10.1086/590218

$\varnothing$ verli, $\varnothing .$, Korzan, W.J., Höglund, E., Winberg, S., Bollig, H., Watt, M., Forster, G.L., Barton, B.A., Øverli, E., Renner, K.J., Summers, C.H., 2004. Stress coping style predicts aggression and social dominance in rainbow trout. Horm. Behav. https://doi.org/10.1016/j.yhbeh.2003.12.002

Person-Le Ruyet, J., Boeuf, G., Infante, J.Z., Helgason, S., Le Roux, A., 1998. Short-term physiological changes in turbot and seabream juveniles exposed to exogenous ammonia. Comp. Biochem. Physiol. - A Mol. Integr. Physiol. https://doi.org/10.1016/S1095-6433(97)00458-3

Person-Le Ruyet, J., Chartois, H., Quemener, L., 1995. Comparative acute ammonia toxicity in marine fish and plasma ammonia response. Aquaculture. https://doi.org/10.1016/0044-8486(95)01026-2

Poulsen, S.B., Jensen, L.F., Nielsen, K.S., Malte, H., Aarestrup, K., Svendsen, J.C., 2011. Behaviour of rainbow trout 
Oncorhynchus mykiss presented with a choice of normoxia and stepwise progressive hypoxia. J. Fish Biol. https://doi.org/10.1111/j.1095-8649.2011.03069.x

Qu, J., Fletcher, Q.E., Réale, D., Li, W., Zhang, Y., 2018. Independence between coping style and stress reactivity in plateau pika. Physiol. Behav. 197, 1-8. https://doi.org/10.1016/j.physbeh.2018.09.007

R Core team, 2013. R: A Language and Environment for Statistical Computing. R Found. Stat. Comput.

Randall, D.J., Tsui, T.K.N., 2002. Ammonia toxicity in fish, in: Marine Pollution Bulletin. https://doi.org/10.1016/S0025-326X(02)00227-8

Richter, S.H., Hintze, S., 2019. From the individual to the population - and back again? Emphasising the role of the individual in animal welfare science. Appl. Anim. Behav. Sci. https://doi.org/10.1016/j.applanim.2018.12.012

Ruiz-Gomez, M. de L., Kittilsen, S., Höglund, E., Huntingford, F.A., Sørensen, C., Pottinger, T.G., Bakken, M., Winberg, S., Korzan, W.J., $\varnothing$ verli, $\varnothing$., 2008. Behavioral plasticity in rainbow trout (Oncorhynchus mykiss) with divergent coping styles: When doves become hawks. Horm. Behav. https://doi.org/10.1016/j.yhbeh.2008.05.005

Sadoul, B., Evouna Mengues, P., Friggens, N.C., Prunet, P., Colson, V., 2014. A new method for measuring group behaviours of fish shoals from recorded videos taken in near aquaculture conditions. Aquaculture. https://doi.org/10.1016/j.aquaculture.2014.04.008

Sadoul, B., Friggens, N.C., Valotaire, C., Labbé, L., Colson, V., Prunet, P., Leguen, I., 2017. Physiological and behavioral flexibility to an acute $\mathrm{CO} 2$ challenge, within and between genotypes in rainbow trout. Comp. Biochem. Physiol. -Part A Mol. Integr. Physiol. https://doi.org/10.1016/j.cbpa.2017.04.002 
Sadoul, B., Leguen, I., Colson, V., Friggens, N.C., Prunet, P., 2015. A multivariate analysis using physiology and behavior to characterize robustness in two isogenic lines of rainbow trout exposed to a confinement stress. Physiol. Behav. https://doi.org/10.1016/j.physbeh.2014.12.006

Shannon, N.J., Gunnet, J.W., Moore, K.E., 1986. A Comparison of Biochemical Indices of 5-Hydroxytryptaminergic Neuronal Activity Following Electrical Stimulation of the Dorsal Raphe Nucleus. J. Neurochem. https://doi.org/10.1111/j.1471-4159.1986.tb00704.x

Shingles, A., McKenzie, D.J., Taylor, E.W., Moretti, A., Butler, P.J., Ceradini, S., 2001. Effects of sublethal ammonia exposure on swimming performance in rainbow trout (Oncorhynchus mykiss). J. Exp. Biol.

Spotte, S., Anderson, G., 1989. Plasma Cortisol Changes in Seawater-Adapted Mummichogs ( Fundulus heteroclitus ) Exposed to Ammonia. Can. J. Fish. Aquat. Sci. https://doi.org/10.1139/f89-255

Taheri Mirghaed, A., Fayaz, S., Hoseini, S.M., 2019. Effects of dietary 1,8-cineole supplementation on serum stress and antioxidant markers of common carp (Cyprinus carpio) acutely exposed to ambient ammonia. Aquaculture. https://doi.org/10.1016/j.aquaculture.2019.04.071

Thurston, R. V, Russo, R.C., 1983. Acute toxicity of ammonia to rainbow trout. Trans. Am. Fish. Soc.

Van Raaij, M.T.M., Pit, D.S.S., Balm, P.H.M., Steffens, A.B., Van Den Thillart, G.E.E.J.M., 1996. Behavioral strategy and the physiological stress response in rainbow trout exposed to severe hypoxia. Horm. Behav. https://doi.org/10.1006/hbeh.1996.0012

Vaz-Serrano, J., Ruiz-Gomez, M.L., Gjøen, H.M., Skov, P. V., Huntingford, F.A., Øverli, Höglund, E., 2011. Consistent boldness behaviour in early emerging fry of domesticated Atlantic salmon (Salmo salar): Decoupling of behavioural and physiological traits of the proactive stress coping style. Physiol. Behav. 103, 359-364. https://doi.org/10.1016/j.physbeh.2011.02.025 
Via, J.D., Van den Thillart, G., Cattani, O., Cortesi, P., 1998. Behavioural responses and biochemical correlates in Solea solea to gradual hypoxic exposure. Can. J. Zool. https://doi.org/10.1139/z98-141

Weber, R. a., MacEira, J.J.P., Mancebo, M.J., Peleteiro, J.B., Martín, L.O.G., Aldegunde, M., 2012. Effects of acute exposure to exogenous ammonia on cerebral monoaminergic neurotransmitters in juvenile Solea senegalensis. Ecotoxicology 21, 362-369. https://doi.org/10.1007/s10646-011-0797-8

Wendelaar Bonga, S., 1997. The stress response in fish. Physiol. Rev. 77, 591-625.

Wicks, B.J., Joensen, R., Tang, Q., Randall, D.J., 2002. Swimming and ammonia toxicity in salmonids: The effect of sub lethal ammonia exposure on the swimming performance of coho salmon and the acute toxicity of ammonia in swimming and resting rainbow trout. Aquat. Toxicol. https://doi.org/10.1016/S0166$445 \times(01) 00236-3$

Wilson, S.M., Hinch, S.G., Eliason, E.J., Farrell, A.P., Cooke, S.J., 2013. Calibrating acoustic acceleration transmitters for estimating energy use by wild adult Pacific salmon. Comp. Biochem. Physiol. - A Mol. Integr. Physiol. https://doi.org/10.1016/j.cbpa.2012.12.002

Winberg, S., Höglund, E., Øverli, Ø., 2016. Variation in the Neuroendocrine Stress Response, in: Fish Physiology. pp. 35-74. https://doi.org/10.1016/B978-0-12-802728-8.00002-3

Wong, R.Y., French, J., Russ, J.B., 2019. Differences in stress reactivity between zebrafish with alternative stress coping styles. R. Soc. Open Sci. https://doi.org/10.1098/rsos.181797

Zupa, W., Carbonara, P., Spedicato, M.T., Lembo, G., 2015. Modelling swimming activities and energetic costs in European sea bass (Dicentrarchus labrax L., 1758) during critical swimming tests. Mar. Freshw. Behav. Physiol. https://doi.org/10.1080/10236244.2015.1073456 


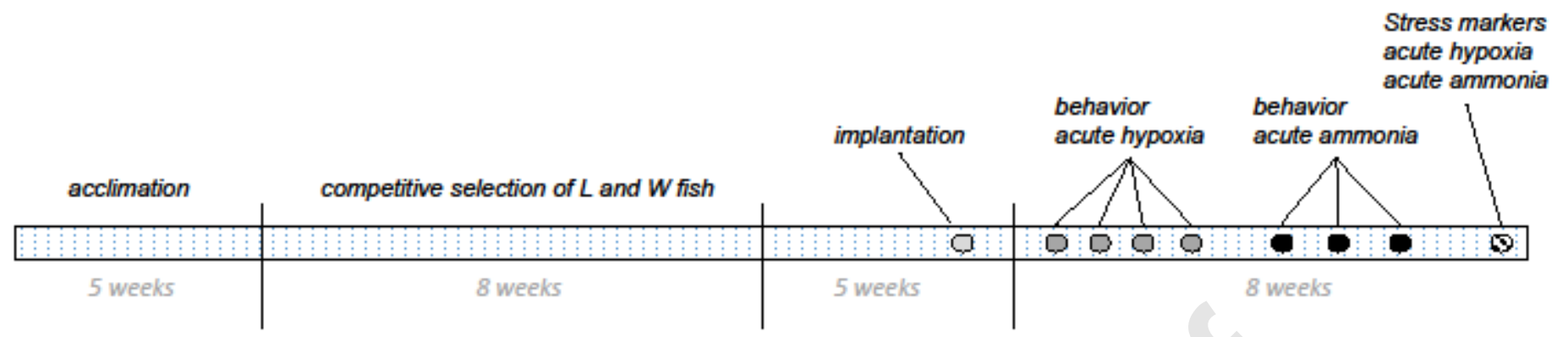

Figure 1. Experimental outline for the selection of $L$ and $W$ fish, the implantation of transmitters, and the hypoxia and ammonia exposure tests. 
Activity in the hypoxia test
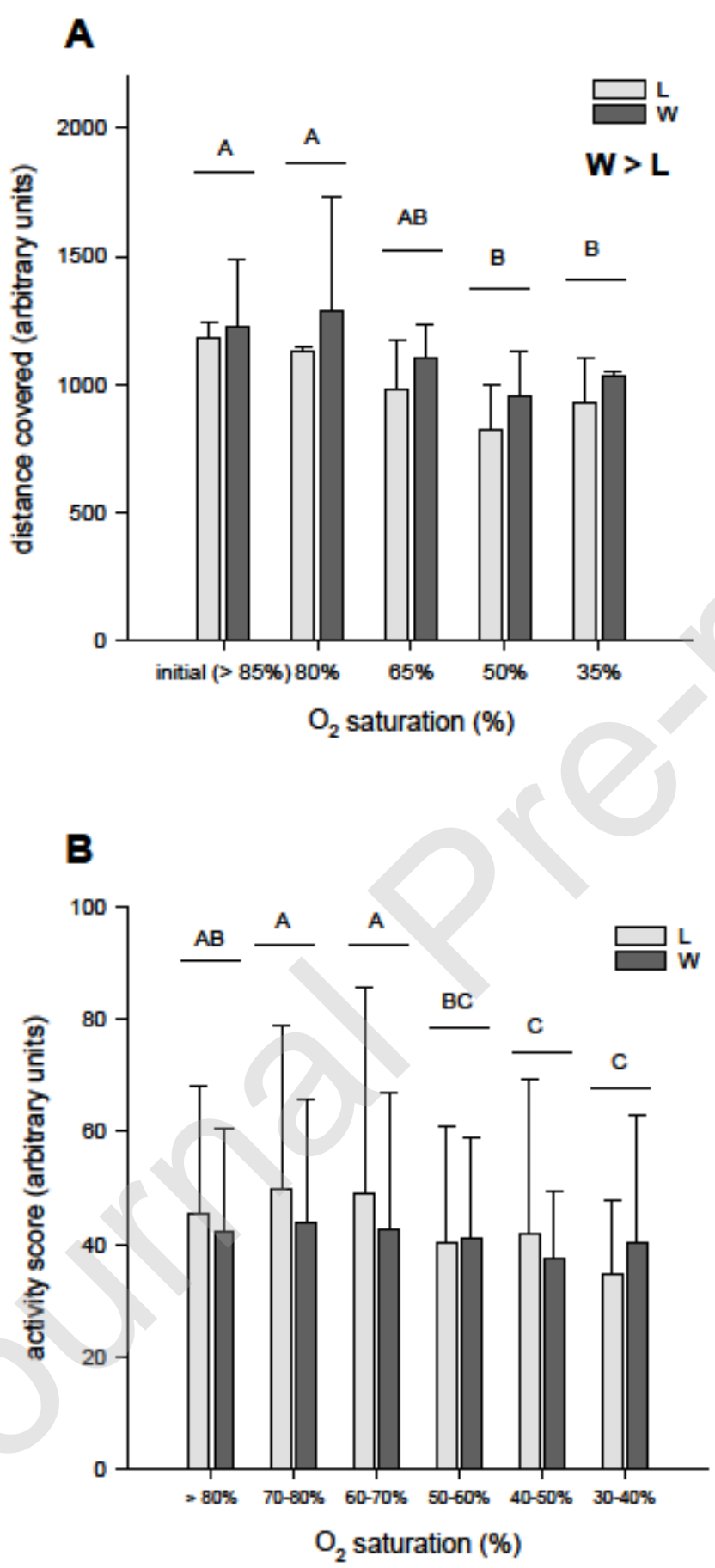
Figure 2. Activity levels of $L$ and $W$ fish during increasing hypoxia challenge tests (see the main text for details). A) Distance covered by $L$ and $W$ groups for each interval during the hypoxia tests (mean and SD; $n=5$ fish per competition group in $n=4$ trial repetitions). B) Activity scores of $L$ and $W$ groups for each interval during the hypoxia tests (mean and SD; $n=5$ fish per competition group in $n=4$ repetitions). Different letters indicate significant differences between the different levels of oxygen saturation (GLMM followed by Tukey HSD post hoc test). 
A

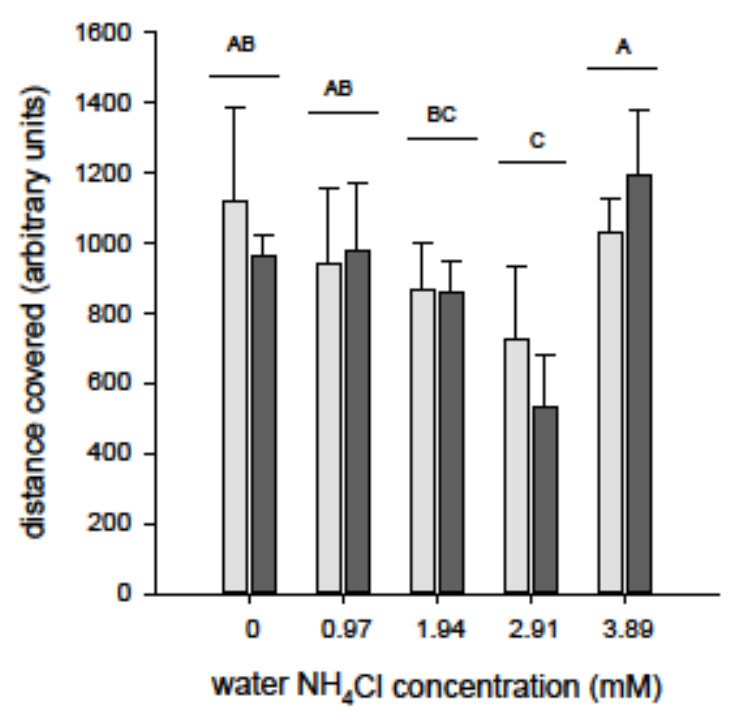

C

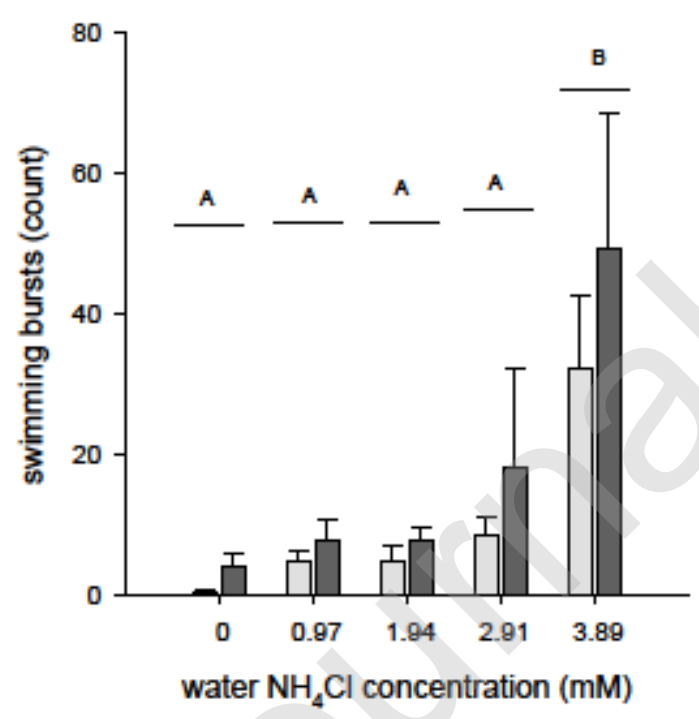

B

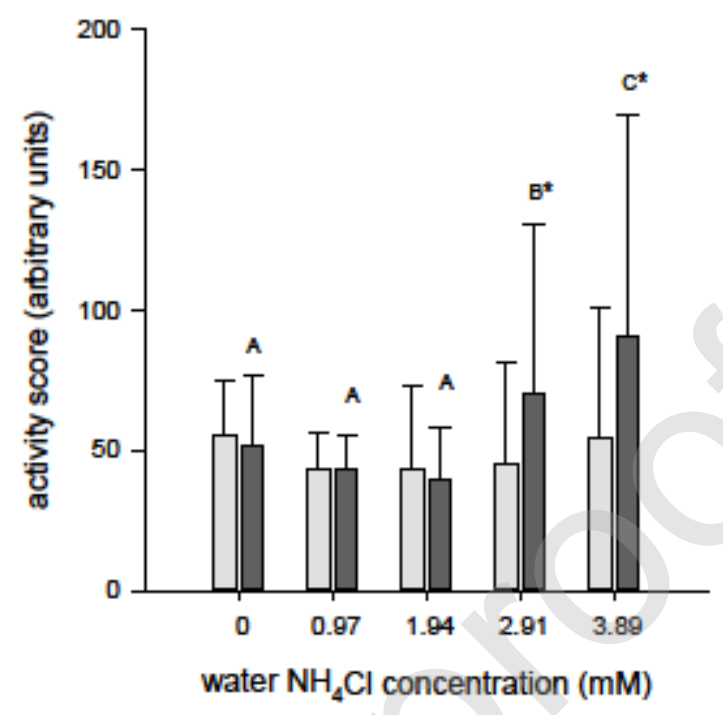

D

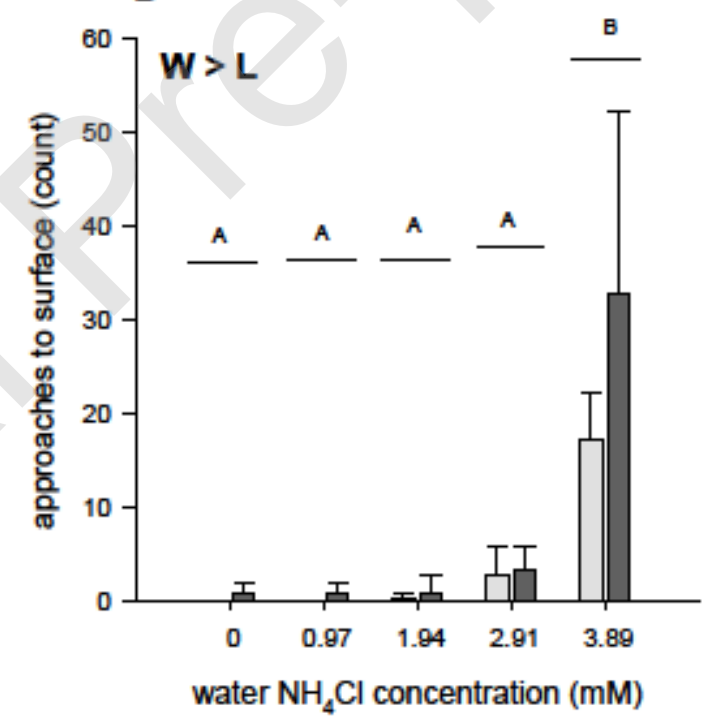

Figure 3. Activity levels of $L$ and $W$ fish and counts of swimming bursts and approaches to surface during increasing ammonia challenge tests (see the main text for details). A) Distance covered by $L$ and $W$ groups for each interval during the ammonia tests (mean and SD; $n=5$ fish per competition group in $n=3$ repetitions). B) Activity scores of $L$ and $W$ groups for each interval during the ammonia tests $(n=5$ fish per competition group in 
$\mathrm{n}=2$ repetitions). C) Swimming bursts count. D) Approaches to surface count. For C and D: Total number of displays were counted in the experimental tanks during a 4-min period at each ammonia concentration $(n=5$ per competition group). Different letters indicate significant differences between the different ammonia concentration; * indicate a significant difference between the competition groups within a given ammonia concentration (A and B: GLMM followed by Tukey HSD post hoc test; C and D: Two-way repeated-measures ANOVA, Holm-Sidak post hoc test). 

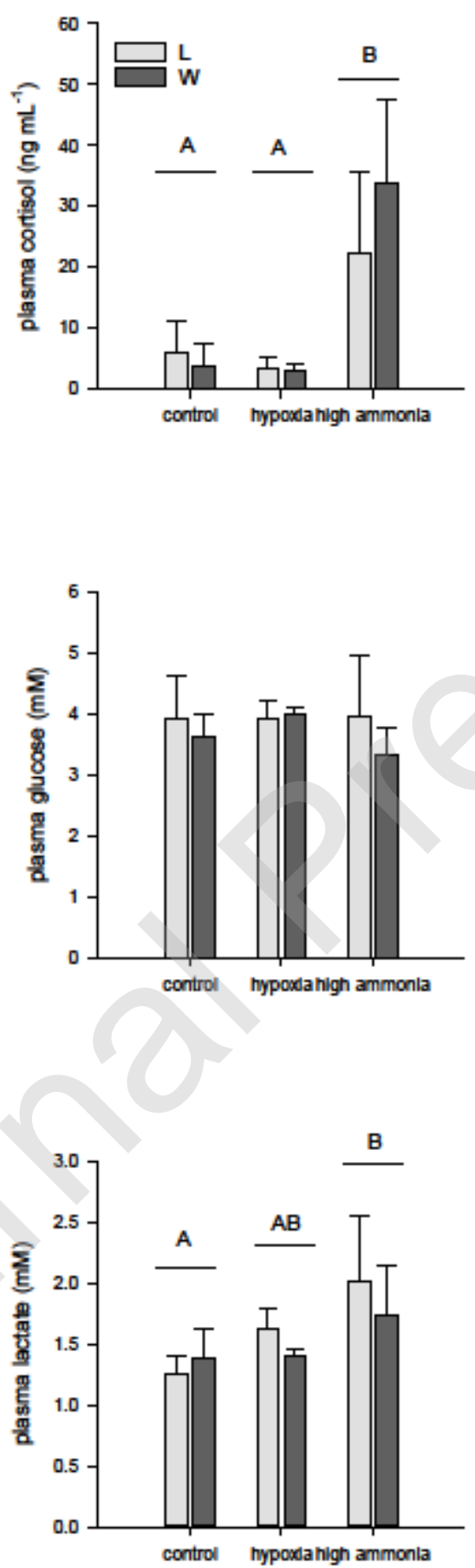
Figure 4. Plasma concentration of cortisol, glucose and lactate of $L$ and $W$ fish just before (control) or after exposure to hypoxia and ammonia. In the hypoxia group, oxygen saturation was progressively decreased until it reached 50 \% saturation. In the ammonia group, ammonia concentration was sequentially increased by adding $\mathrm{NH}_{4} \mathrm{Cl}$ until it reached $2.91 \mathrm{mM}$ (see the main text for more details about the exposure protocol). Data represent the mean and SD of $n=9$ fish per competition group for controls and $n=12$ fish for hypoxia and ammonia. Different letters indicate significant difference between the conditions (control, hypoxia and ammonia; two-way ANOVA, Holm-Sidak post hoc test).

Supplementary Figure 1. Oxygen saturation levels measured during increasing hypoxia challenge tests for $\mathrm{W}$ (winners) and L (losers) fish.

Supplementary Figure 2. Serotonin (5-HT), 5-hydroxyindoleacetic acid (5-HIAA) and the serotonergic mass ratio (5-HIAA/5-HT) in the telencephalon of $L$ (losers) and W (winners) fish just before (control) or after exposure to hypoxia and ammonia. In the hypoxia group, oxygen saturation was progressively decreased until it reached 50 \% saturation. In the ammonia group, ammonia concentration was sequentially increased by adding $\mathrm{NH}_{4} \mathrm{Cl}$ until it reached $2.91 \mathrm{mM}$ (see the main text for more details about the exposure protocol). Data represent the mean and SD of $\mathrm{n}=9$ fish per competition group for controls and $\mathrm{n}=12$ fish for hypoxia and ammonia. Different letters indicate significant difference between the conditions (control, hypoxia and ammonia; two-way ANOVA, HolmSidak post hoc test). 